\title{
An efficient noninvasive method for simultaneous species, individual, and sex identification of sympatric Mojave Desert canids via in-solution SNP capture
}

Lillian D Parker ${ }^{1,2}$, Michael G Campana ${ }^{1,2,3}$, Jessica D Quinta ${ }^{1}$, Brian Cypher $^{4}$, Isabel Rivera $^{1}$, Robert C Fleischer ${ }^{1}$, Katherine Ralls ${ }^{1}$, Tammy R Wilbert ${ }^{1}$, Ryan Boarman ${ }^{5}$, William I Boarman ${ }^{5}$, and Jesús E Maldonado ${ }^{1,2,3,5}$

${ }^{1}$ Center for Conservation Genomics, Smithsonian Conservation Biology Institute and National

${ }^{2}$ School of Systems Biology

${ }^{3}$ Department of 13 Environmental Science and Policy, George Mason University

${ }^{4}$ Endangered Species Recovery Program, California State University

${ }^{5}$ Conservation Science Research and Consultation

August 5, 2021

\section{Hosted file}

210803_CSP_MS_preprint.pdf available at https://authorea.com/users/313978/articles/533022-anefficient-noninvasive-method-for-simultaneous-species-individual-and-sex-identificationof-sympatric-mojave-desert-canids-via-in-solution-snp-capture 